\title{
Assessment of Utility of Fine Needle Aspiration Cytology in Patients of Peripheral Lymphadenopathy- Experience of A Tertiary Care Hospital
}

\author{
Upender Sharma, Ajit Singh, Hemlata T Kamra*, Atul Beniwal and Sonam Sharma \\ Department of Pathology, Kalpana Chawla Govt Medical College, Karnal (Haryana)
}

\begin{abstract}
Background: Fine needle aspiration cytology (FNAC) is a quick, sensitive, safe, reliable and cost-effective outdoor procedure that has a lower risk of complications as compared to a surgical biopsy. This study was conducted to analyse the various cytomorphological patterns establishing the diagnosis on FNAC in peripheral lymphadenopathy patients along with their clinical presentation.

Methods: This study included 300 patients of peripheral lymphadenopathy in a tertiary care hospital of north-central Haryana. FNAC was done under all aseptic conditions and various cytomorphological patterns were analysed.

Result: On stratification of lymph node lesions, 240/300 cases (80\%) were reported as non-neoplastic and 60/300 cases (20\%) as neoplastic lesions. Among the non-neoplastic lesions, granulomatous pathology was the commonest lesion encountered in 137/240 cases (57.1\%), followed by reactive lymphoid hyperplasia and suppurative lymphadenitis. Metastatic involvement of lymph node was the commonest pathological finding diagnosed in 52/60 of malignant neoplastic cases $(86.66 \%)$. Overall, the cervical lymph nodes were most commonly involved in $68.66 \%$ patients, followed by other lymph nodes.

Conclusion: Lymphadenopathy can have varied etiologies ranging from non-neoplastic to neoplastic conditions. FNAC as a first line investigative procedure in lymphadenopathy patients obviates the need for surgical excision and guides subsequent patient therapy and management. The cervical group of lymph nodes are most commonly involved in both non neoplastic as well as neoplastic lymph node lesions. In younger age group ( $<30$ years) non neoplastic causes of lymphadenopathy are more common whereas in elderly the malignant neoplastic causes are more common. The secondary metastatic carcinoma is more common than primary lymphoma of the lymph nodes.
\end{abstract}

Keywords: Fine Needle Aspiration Cytology, Lymphadenopathy, Granuloma, Metastasis, Lymphoma.

\section{Introduction}

Lymphadenopathy is defined as an abnormality in the size and character of the lymph nodes caused by the activation and proliferation of lymphocytes and phagocytic white blood cells within the node or by invasion of the node by tumor. Lymph nodes are most widely distributed and easily accessible component of lymphoid tissue. ${ }^{[1]}$ Aspiration of lymph nodes for diagnostic purpose was first reported in 1904 by Grieg and Gray in the diagnosis of Trypanosomiasis. In 1921, Guthrie attempted to correlate lymph node aspiration cytology with various disease processes. ${ }^{[2-3]}$ Fine needle aspiration cytology (FNAC) has now been universally accepted as the initial workup tool in the diagnosis and management of patients with lymphadenopathy due to early availability of results, simplicity and minimal trauma with less complications. ${ }^{[4]}$ FNAC has also been advocated as a useful method in comparison to more expensive surgical excision biopsies in developing countries with limited financial and health care resources. ${ }^{[5]}$ It almost offers an accurate diagnosis for infectious disease, granulomatous lymphadenitis, reactive lymphoid hyperplasia and metastatic malignancy. Thus, it can avoid the need for excision biopsy in most cases and allow rapid onset of therapy. ${ }^{[6]}$ The diagnosis of metastatic tumor to the lymph node on cytological smear is crucial and highly reliable. This would initiate the search of primary tumor, especially in cases of occult carcinoma. ${ }^{[7]}$

The etiological profile of lymphadenopathy varies in different regions and in different age groups. In developing countries like India tuberculosis, acute respiratory infections and suppurative skin infections are main causes for lymphadenopathy while in developed countries metastasis from carcinoma is the more frequent cause for lymphadenopathy. Children can present with massive local lymphadenopathy even after mild infections. In contrast, adults or elderly patients often react to infections with only slight to modest lymph node enlargement. Therefore, distinct lymphadenopathy in an elderly patient will raise suspicion of malignancy ${ }^{[8]}$ On the other hand, in second and third decade of life granulomatous lymphadenitis is a common cause of lymphadenopathy. Thus, etiology can vary from a reactive process to a granulomatous etiology to a malignant condition. ${ }^{[9]}$

The cytomorphological features obtained in needle aspiration, usually correlate very well with the histological 
features. Using cytomorphology alone, it is often possible to decide whether lymphadenopathy has resulted from reactive lymphadenitis, granulomatous pathology, acute suppurative etiology, metastatic malignancy or lymphoma. Patients with reactive lymphadenopathy and metastasis from a known malignancy can thus be spared lymph node excision. In cases with indeterminate cytology or diagnosis of lymphoma, surgical excision has usually been regarded as mandatory. However, several recent studies have shown conclusively that a combined cytological and immunological evaluation of aspirated lymphoid cells results in distinctly improved diagnostic accuracy in cases of lymphoma. Aspirated cells perform excellently in immunohistochemistry, flowcytometry and gene rearrangement analysis. ${ }^{[10-11]}$ This study was planned to evaluate the cytomorphological patterns in lymphadenopathy by fine needle aspiration in a tertiary care hospital of north central Haryana.

\section{Materials and Methods}

The present study included 300 patients of peripheral lymphadenopathy presented in Department of Pathology of a tertiary care hospital of north central Haryana from January 2018 to December 2018. All the patients were clinically examined and the procedure of FNAC was explained to them including reliability, limitations and complications of the procedure. Informed consent of the patients was taken. FNA procedure, smear preparation and staining were done as per the standard procedure. The smears were stained with May- Grunwald Giemsa, Haematoxylin \& Eosin and Papanicolaou stain. Special staining like Ziehl Neelsen stain and PAS were performed wherever required. Smears were examined microscopically for evaluating the cytological findings in all the cases.

\section{Result}

The age range of the patients was from 2 months to 87 years with a mean age of 37.5 years. There were 161 male patients and 139 female patients with male:female ratio of 1.15:1. The cervical lymph node was the commonest site in 206 cases $(68.66 \%)$, followed by axillary in 29 cases $(9.66 \%)$, submandibular in 25 cases $(8.33 \%)$, supraclavicular in 24 cases $(8.00 \%)$, inguinal in 10 cases $(3.33 \%)$, submental group in 5 cases $(1.66 \%)$, and suboccipital in 1 case $(0.33 \%)$.

It was observed that $240 / 300$ cases $(80 \%)$ were of non neoplastic lymph node lesions and $60 / 300$ cases $(20 \%)$ were of malignant neoplastic lesions. The neoplastic lymph node lesions were more (35) in males as compared to females (25) with the male:female ratio of $1.4: 1$. Granulomatous lymphadenitis was the commonest lesions encountered among non neoplastic lesions with 137/240 cases $(57.08 \%)$ followed by reactive lymphoid hyperplasia (Fig 1) in $87 / 240$ cases $(36.25 \%)$ and suppurative lymphadenitis in 16/240 cases (6.66\%). Most of the cases reported as granulomatous pathology were in the second and third decade of life. It was noticed that majority of granulomatous pathology cases involved posterior cervical group of lymph nodes.

On further evaluating 137 cases of granulomatous pathology, 85 cases $(62 \%)$ revealed positivity for acid fast bacilli on Ziehl Neelsen staining. In the malignant neoplastic lesions secondary malignancy (metastatic involvement) of lymph node was more common pathological finding in 52/60 cases $(86.66 \%)$ whereas primary malignancy (lymphoma) was diagnosed in $8 / 60$ cases $(13.33 \%)$. It was noticed that most of the patients with metastatic lymph node lesions were above 50 years of age with male:female ratio of $1.4: 1$. The patients presented with variable symptoms e.g. anorexia, loss of weight, hoarseness of voice, dysphagia and difficulty in breathing. The study revealed that out of 52 cases of metastasis, 25 cases $(48.07 \%)$ were of squamous cell carcinoma (Fig 2), 2 cases $(3.84 \%)$ of infiltrating ductal carcinoma breast, 2 cases $(3.84 \%)$ of adenocarcinoma, 2 cases $(3.84 \%)$ of papillary carcinoma thyroid. However, 21 cases $(40.38 \%)$ cases presented in advanced stage so could not be subtyped based on cytomorphorphology and were diagnosed as metastatic carcinomatous deposits/ poorly differentiated carcinoma. The majority of the cases of lymphoma $(7 / 8$, $87.5 \%$ ) were seen in $>50$ years of age group and males were affected more commonly with male:female ratio of 1.66:1. Two cases of Hodgkin Lymphoma were observed. These patients of Hodgkin Lymphoma had enlarged rubbery lymph nodes in the cervical region.

\section{Discussion}

FNAC has become an acceptable and widely practised minimally invasive technique which is safe, simple, rapid, relatively pain free and cost effective technique providing rapid information and directing further approach to patients. In this study mean age of presentation was 37.5 years (age range 2 months to 87 years) with male: female ratio of 1.15:1. The lymphadenopathy most commonly involved the cervical group (68.66\%). On cytological evaluation of lymphadenopathy cases it was observed that non neoplastic cases $(80 \%)$ were more common than the neoplastic malignant cases $(20 \%)$ with ratio of non-neoplastic: neoplastic lesions as $4: 1$, which is in concordonce with most other studies. ${ }^{[12-14]}$ ( Table 1 ). The study done by K $\mathrm{R}$ Anila et al. ${ }^{[15]}$ found neoplastic cases more than the non neoplastic cases which may be because the study has been done in a cancer institute. In the present study, among non neoplastic lesions, maximum number of cases (137/240, 
Table 1: comparative evaluation of non-neoplastic and neoplastic lesions in different studies.

\begin{tabular}{|l|l|l|l|l|}
\hline S. No & Study & Non-neoplastic lesions & Neoplastic lesions & Ratio \\
\hline 1 & Gorle VK et al. ${ }^{[12]} 2018$ & $82 \%$ & $18 \%$ & $4.55: 1$ \\
\hline 2 & Paikrao YM et al. ${ }^{[13]} 2018$ & $80.11 \%$ & $19.88 \%$ & $4.02: 1$ \\
\hline 3 & ${\text { Gojiya et al. } .^{[14]} 2018}^{[118} 2015$ & $76.7 \%$ & $23.3 \%$ & $3.29: 1$ \\
\hline 4 & K R Anila et al. ${ }^{[15]} 20.9 \%$ & $54.1 \%$ & $0.84: 1$ \\
\hline 5 & Present study & $80 \%$ & $20 \%$ & $4: 1$ \\
\hline
\end{tabular}

Table 2: Comparative evaluation of cytological diagnosis of lymphadenopathy in different studies.

\begin{tabular}{|l|l|l|l|l|l|l|}
\hline S. No & Lesions & $\begin{array}{l}\text { Bottle et } \\
\text { al }{ }^{[1]]}\end{array}$ & $\begin{array}{l}\text { Hirachand et } \\
\text { al }{ }^{[18]}\end{array}$ & $\begin{array}{l}\text { Khajuria et } \\
\text { al }{ }^{[19]}\end{array}$ & $\begin{array}{l}\text { Kumuguru et } \\
\text { al }{ }^{[20]}\end{array}$ & $\begin{array}{l}\text { Present } \\
\text { study }\end{array}$ \\
\hline 1 & Reactive lymphoid hyperplasia & $50.00 \%$ & $41.50 \%$ & $37.20 \%$ & $46.32 \%$ & $29 \%$ \\
\hline 2 & Granulomatous pathology & $17.00 \%$ & $37.20 \%$ & $52.30 \%$ & $48.85 \%$ & $45.66 \%$ \\
\hline 3 & Suppurative lymphadenitis & --- & $03.00 \%$ & $01.00 \%$ & $01.29 \%$ & $5.33 \%$ \\
\hline 4 & Metastatic carcinoma & $12.30 \%$ & $12.30 \%$ & $03.80 \%$ & $01.29 \%$ & $17.33 \%$ \\
\hline 5 & Lymphoma & $06.00 \%$ & $06.00 \%$ & $02.00 \%$ & $01.73 \%$ & $2.66 \%$ \\
\hline 6 & Cryptococcal lymphadenitis & --- & --- & --- & $00.43 \%$ & --- \\
\hline
\end{tabular}

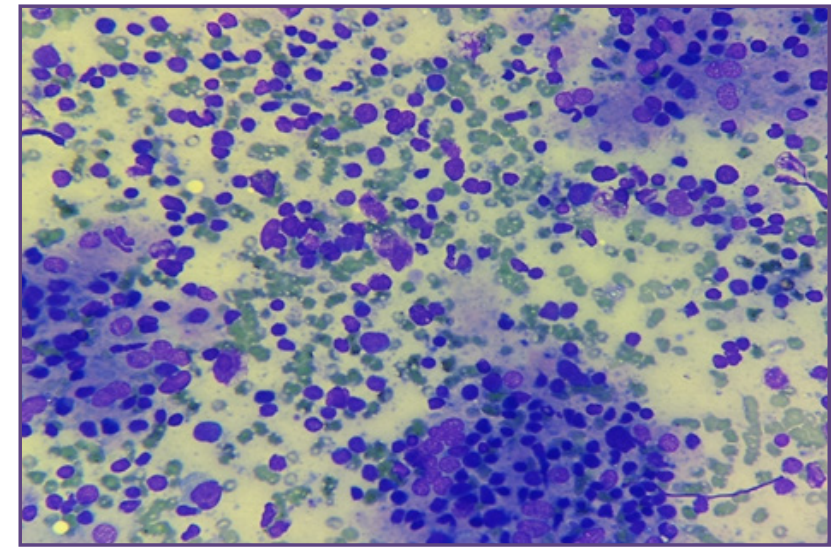

Fig. 1: Cytological smear showing polymorphus population of lymphoid cells in a case of reactive lymphoid hyperplasia. (MGG, 400X).

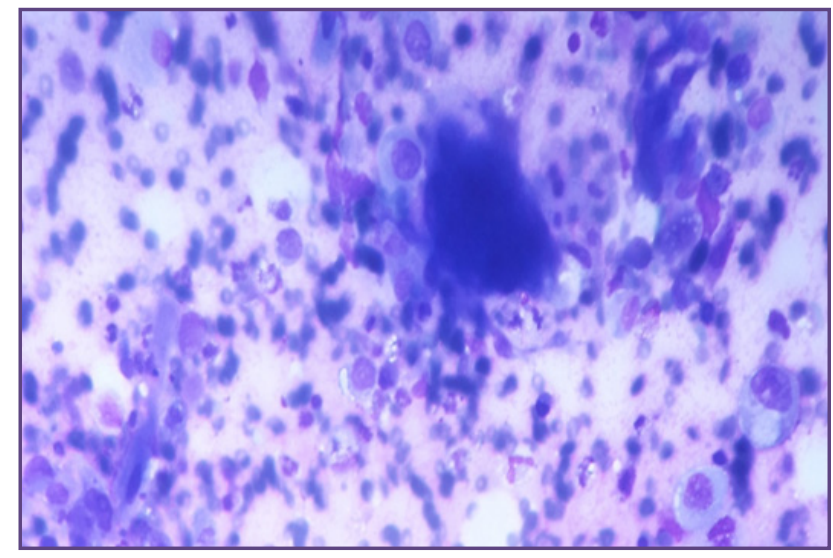

Fig. 3: Cytological smear showing metastatic deposits from squamous cell carcinoma. (MGG, 400X).

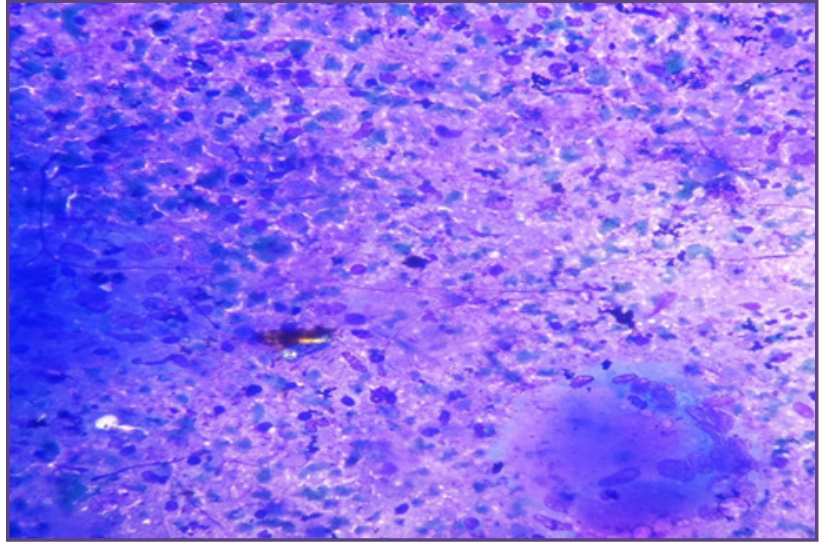

Fig. 2: Cytological smear showing Langhans' cell granuloma in a case of tubercular lymphadenitis. (MGG, 400X).

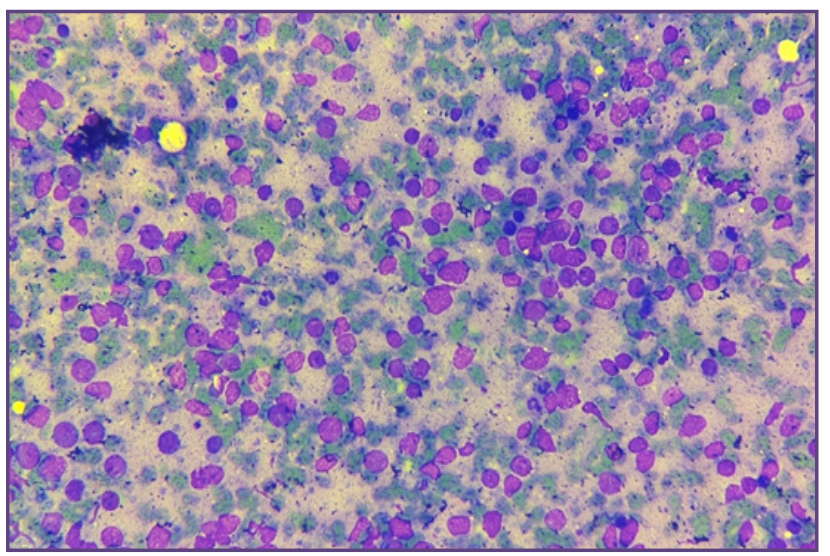

Fig. 4: Cytological smear showing monomorphic population of atypical lymphoid cells in a case of Non Hodgkin's Lymphoma. (MGG, 400x). 
$57.08 \%$ ) were of granulomatous pathology, followed by $(87 / 240,36.25 \%)$ reactive lymphoid hyperplasia and (16/240, 6.66\%) suppurative lymphadenitis. A comparative evaluation of these results has been done and shown in table 2 .

The granulomatous pathology occurs because of a number of infectious and non infectious causes. The common infectious causes include tuberculosis, atypical mycobacteriosis, fungal infections, toxoplasmosis, cat scratch disease, tularaemia and leprosy. The common non infectious causes include chronic granulomatous disease, sarcoidosis and foreign body granuloma. On further evaluating 137 cases of granulomatous pathology, 85 cases (62\%) revealed positivity for acid fast bacilli on Ziehl Neelsen staining. Cytologically, tuberculous lymphadenitis is characterized by caseation necrosis, epithelioid cell granulomas, and Langhans' type giant cells (Fig 2). This study found epithelioid cell granuloma with caseous necrosis as the most common pattern in tuberculosis. It was also observed that posterior cervical group of lymph nodes were the most common lymph nodes involved in tuberculosis. Most of the patients of granulomatous pathology were in the second and third decade of life. Cytological analysis of reactive lymph node reveals lymphoid cells with variable maturation intermixed with immunoblasts and tingible body macrophages. Reactive lymphadenopathy was the second most common cause of lymphadenopathy in our study and was more frequently noted in the younger age group. These findings are consistent with other studies. ${ }^{[16]}$ Patients of suppurative lymphadenitis presented with pain, tenderness and fever and responded well with antibiotic treatment.

The most common cause of malignant neoplastic lesions in the present study was metastatic carcinomatous deposits in $17.33 \%(52 / 300)$ of total cases followed by lymphoma in $2.66 \%(8 / 300)$ cases. In $25 / 52$ cases metastatic deposits from squamous cell carcinoma were revealed (Fig 3). In addition, 2 cases had metastatic deposits from Infiltrating ductal carcinoma breast, 2 cases had metastatic deposits from papillary carcinoma thyroid, 2 cases were diagnosed metastatic carcinomatous deposits from adenocarcinoma and rest of the 21 cases were diagnosed as metastatic carcinomatous deposits/poorly differentiated carcinomatous deposits.

The lymphoma patients usually present with severe anorexia, loss of weight and fever along with the presence of hepatosplenomegaly in some of these. 6/8 lymphoma cases in this study were having Non Hodgkin's Lymphoma (Fig 4) and 2/8 cases of Hodgkin Lymphoma were observed. Hypocellular aspirates from clinically significant/large lymph nodes should alert the pathologist to the possibility of fibrosis obscuring the primary pathology. The biopsy is mandatory in such cases. The presence of atypical mononuclear cells, large number of eosinophils and granulomas together should raise a high index of suspicion for further evaluation.

The incidence of malignancy increases steadily with the age of the patients and in this study $80 \%$ of malignant reported cases were $>50$ years of age. No case of metastatic lymph node lesion was reported below 20 years of age. Hence, there is a pressing need for FNAC of enlarged lymph nodes in the elderly because of high chances of it to be malignant.

\section{Conclusion}

FNAC is a quick, safe, simple and reliable outpatient procedure. It helps in establishing the diagnosis in a large number of cases when used in conjunction with clinicoradiological findings, obviates the need for surgical excision and guides subsequent patient therapy and management. Non neoplastic causes of lymphadenopathy are more common than the neoplastic causes. Granulomatous inflammation and reactive lymphoid hyperplasia are most common non neoplastic causes of lymphadenopathy. Metastatic carcinoma and NHL are seen mostly in patients over 50 years of age. Secondary metastatic carcinoma is more common malignant etiology of lymphadenopathy than primary lymphoma.

\section{Acknowledgements}

No

\section{Funding}

None

\section{Competing Interests}

None

\section{References:}

1. Rakhshan M. The diagnostic accuracy of fine needle aspiration cytology in neck lymphoid masses. Iranian J of Pathol 2009; 4: 147-150.

2. Narang RK, Pradhan S. Place of fine needle aspiration cytology in the diagnosis of lymphadenopathy. Ind $\mathrm{J}$ Tub 1990; 37: 29-32.

3. Guthrie CG. Gland puncture as a diagnostic measure. Bull Johns Hopkins Hosp 1921; 32: 266-268.

4. Kollur SM, El Hag IB. Fine needle aspiration cytology of metastatic nasopharyngeal carcinoma in cervical lymph nodes: comparison with metastatic squamous cell carcinoma and Hodgkin' and Non-Hodgkin' lymphoma. Diagn Cytopathol 2003; 28:18-22.

5. Al-Mulhim AS, Hafez NH, Tahoun NS, Reliability of fine needle aspiration cytology (FNAC)as a diagnostic tool in 
cases of cervical lymphadenopathy, Journal of the Egyptian National Cancer Institute 2011; 23(3), 105-114.

6. Mohanty R, Wilkinson A, Utility of Fine Needle Aspiration Cytology of Lymph nodes IOSR J of Dental and Med Sciences (IOSR-JDMS) 2013;8(1):13-18.

7. Hirachand S, Lakhey M, Akhter J, Thapa B. Evaluation of fine needle aspiration cytology of lymph nodes in Kathmandu Medical College, Teaching hospital. Kathmandu Univ Med J 2009; 7 (26):139-42.

8. Skoog L, Tani E. Lymph nodes. In: Gray W, Kocjan G ed-itors. Diagnostic Cytopathology. Third edition. Edinburg: Churchill Livingstone 2010; 409-44.

9. Pandit AA, Candes FP, Khubchandani SR. Fine needle aspiration cytology of lymph nodes. Journal of Postgraduate Medicine, 1987; 33: 134-6.

10. Gray W, Kocjan G. Diagnostic Cytopathology. Third edition. Edinburg: Churchill Livingstone 2010; 409-44.

11. Koss LG (editor). Diagnostic cytology and its Histopathologic basis. Philadelphia: J B Lippincott; 1992.

12. Gorle VK, Inamdar P. A clinicopathological study on cervical lymphadenopathy: an institutional experience. Int Surg J 2018; 5(8): 2841-2845.

13. Paikrao YM, Deshpande PM, Chintale KN. Clinicopathological study of cervical lymphadenopathy at rural tertiary health care centre. Int J Adv Med 2018; 5(1): $154-58$

14. Gojiya P, Goswami A, Shah S. Evaluation of fine needle aspiration cytology of cervical lymphadenopathies at tertiary care center. APLAM 2018; 5(1): A22-A27

15. Anila KR, Nayak N, George PS, Jayasree K. Utility of fine needle aspiration cytology in evaluation of lymphadenopathyan audit from cancer centre in south India. GJO 2015; 50-57

16. Malhotra AS, Lahori M, Nigam A, Khajuria A: Profile of lymphadenopathy: an institutional based cytomorphological study. Int J Appl Basic Med Res. 2017, 7:100-103

17. Bottles K, McPhaul LW, Volberding P. Fine needle aspiration biopsy of patients with the acquired immuno deficiency syndrome (AIDS). Experience in an outpatient clinic. Annal of Internal Medicine 1988; 108:42-5.

18. Hirachand S, Lakhey M, Akhter J, Thapa B. Evaluation of fine needle aspiration cytology of lymph nodes in Kathmandu Medical College, Teaching hospital. Kathmandu University Medical Journal. 2009; 7:139-42.

19. Khajuria R, Goswami KC, Singh K, Dubey VK. Pattern of Lymphadenopathy on Fine Needle Aspiration Cytology in Jammu. JK science. 2006; 8:23-8.

20. Kumuguru, M.H.Kulkarni, N.S.Kamakeri. FNAC of peripheral lymph nodes in HIV- positive patients.Scentific Medicine. 2009;1:1-7

*Corresponding author:

Dr. Hemlata T Kamra, Professor \& Head, Department of Pathology, Kalpana Chawla Govt. Medical College, Karnal-132001 (Haryana)

Phone: +91 08221883255 / 9306514988

Email: hemlatamunde@rediffmail.com

Financial or other Competing Interests: None.

Date of Submission $\quad: 16 / 08 / 2021$

Date of Final Revision : 25/08/2021

Date of Acceptance $\quad: \quad 27 / 08 / 2021$

Date of Publication $\quad: 30 / 08 / 2021$ 